\title{
Structural, Optical and Electrical Properties of NiO Nanostructure Thin Film
}

\author{
M. Ghougali ${ }^{1,2,3}$, O. Belahssen ${ }^{1,2, *}$, A. Chala ${ }^{1,2}$ \\ ${ }^{1}$ Material Sciences Department, Faculty of Science, University of Biskra, Algeria \\ ${ }_{2}^{2}$ Physic Laboratory of Thin Films and Applications (LPCMA), University of Biskra, Algeria \\ ${ }^{3}$ Laboratory of exploitation and valorization the azalea energetics sources (LEVRES), Faculty of exact Science, \\ University of El-Oued, Algeria
}

(Received 17 July 2016; revised manuscript received 19 December 2016; published online 23 December 2016)

\begin{abstract}
Nickel oxide was deposited on highly cleaned glass substrates using spray pneumatic technique. The effect of precursor molarity on structural, optical and electrical properties has been studied. The XRD lines of the deposited $\mathrm{NiO}$ were enhanced with increasing precursor molarity due to the improvement of the films crystallinity. It was shown that the crystalline size of the deposited thin films was calculated using DebyeScherer formula and found in the range between 9 and $47 \mathrm{~nm}$. The optical properties have been discussed in this work. The absorbance $(A)$, the transmittance $(T)$ and the reflectance $(R)$ were measured and calculated. Band gap energy is considered one of the most important optical parameter, therefore measured and found ranging between 3.64 and $3.86 \mathrm{eV}$. The $\mathrm{NiO}$ thin film reduces the light reflection for visible range light. The increase of the electrical conductivity to maximum value of $0.0896(\Omega \mathrm{cm})^{-1}$ can be explained by the increase in carrier concentration of the films. A good electrical conductivity of the $\mathrm{NiO}$ thin film is obtained due to the electrically low sheet resistance. $\mathrm{NiO}$ can be applied in different electronic and optoelectronic applications due to its high band gap, high transparency and good electrical conductivity.
\end{abstract}

Keywords: NiO thin films, XRD, Optical constants, Electrical conductivity.

DOI: $10.21272 /$ jnep. $8(4(2)) .04059$

PACS numbers: 73.61. - r, 78.20. - e,

78.66. $-\mathrm{w}$

\section{INTRODUCTION}

Nickel oxide $(\mathrm{NiO})$ is the most investigated metal oxide and it has attracted considerable attention because of its low cost material, and also for its applications in several fields such as a catalyst, transparent conducting oxide, photodetectors, electrochromic, gas sensors, photovoltaic devices, electrochemical supercapacitors, heat reflectors, photo-electrochemical cell, solar cells and many opto- electronic devices [1-7]. NiO is an IV group and it can be used as a transparent ptype semiconductor layers, it has a band gap energy ranging from $3.45 \mathrm{eV}$ to $3.85 \mathrm{eV}$ [8]. Band gap energy is significant to adjust the energy level state of $\mathrm{NiO}$.

The reduction in particle size to nanometer scale results more interesting prosperities in compared with their bulk properties [9]. Therefore, there are several techniques have been used for synthesis and manipulation of nanostructures $\mathrm{NiO}$ such as the thermal evaporation, sputtering, pulse laser ablation, thermal decomposition, electrochemical deposition and sol-gel methods etc. Among of these techniques, sol-gel has some advantages such as high purity of raw materials and a homogeneous solution hence easy control over the composition of the deposited films. In this work, a low cost sol-gel/spray pneumatic technique was used to prepare pure $\mathrm{NiO}$ nanoparticles thin films with various precursor concentrations. The structural properties of the produced nickel oxide thin films have been examined. The absorption, transmittance and reflectance spectra of the produced thin films for the $\mathrm{NiO}$ are also measured in range between 300-1100 nm. Moreover, the optical band gap is determined as a function of the precursor concentrations.

\section{EXPERIMENTAL DETAILS}

\subsection{Preparation of Samples}

$\mathrm{NiO}$ thin films were prepared onto a highly cleaned glass substrates using sol-gel spay pneumatic technique. Nickel nitrate was dissolved in $50 \mathrm{ml}$ of water as a solvent and chloride acid was used as a stabilizer for the all samples in this work. The produced mixture (Sol) was stirred at $60{ }^{\circ} \mathrm{C}$ for $2 \mathrm{~h}$ in order to obtain a clear and homogenous solution then the mixture was cooled down at room temperature and placed at dark environment for $48 \mathrm{~h}$ to have the final (Gel). The glass substrates were cleaned by detergent and by alcohol mixed with deionized water.

\subsection{Deposition of Thin Films}

The coating was dropped into glass substrates at $480{ }^{\circ} \mathrm{C}$ that sprayed during $2 \mathrm{~min}$ by pneumatic nebulizer system which transforms the liquid to a stream formed with uniform and fine droplets, followed by the films dried on hot plate at $120^{\circ} \mathrm{C}$ for $10 \mathrm{~min}$ in order to evaporate the solvent.

\subsection{Devices and Measurements}

The X-ray diffraction (XRD) spectra of the $\mathrm{NiO}$ were measured to verify the structure. X-ray diffraction (XRD) was measured by using BRUKER-AXS-8D diffractometer with $\mathrm{Cu} \mathrm{Ka}$ radiation $(\lambda=1,5406 \AA$ ) operated at $40 \mathrm{KV}$ and $40 \mathrm{~mA}$ in the scanning range of $(2 \theta)$ between $20^{\circ}$ and $80^{\circ}$. The spectral dependence of the NiO transmittance $(T)$ and the absorbance $(A)$, on

\footnotetext{
*belahssenokba@gmail.com
} 
the wavelength ranging $300-1100 \mathrm{~nm}$ are measured using an ultraviolet-visible spectrophotometer (PerkinElmer Lambda 25). The reflectance $(R)$ was calculated by the well-known equation as $(T+R+A=1)$. Whereas the electrical conductivity of the films was measured in a coplanar structure of four golden stripes on the deposited film surface; the measurements were performed with keithley model 2400 low voltage source meter instrument.

\section{RESULTS AND DISCUSSIONS}

\subsection{Structural Properties}

Fig. 1 shows the spectra of the grown $\mathrm{NiO}$ nanoparticles with 4 XRD lines, showing the broadening of the line which is a characteristic of the formation of nanoparticles. The X-ray diffraction was used in this work in order to understand the structure of the deposited $\mathrm{NiO}$ thin films with different precursor concentrations.

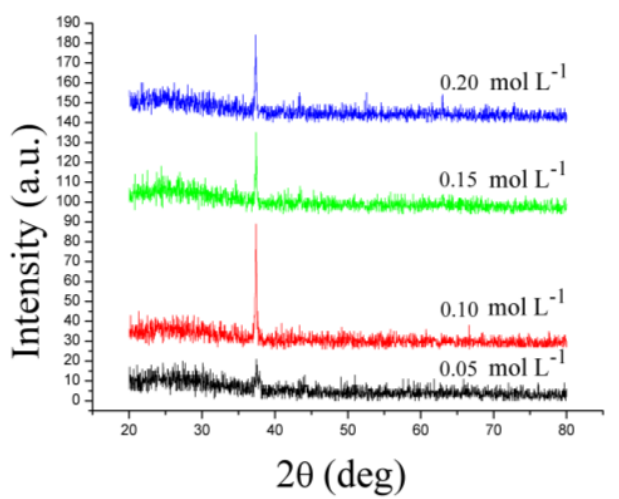

Fig. 1 - XRD patterns of the deposited NiO thin films on glass substrate at different precursor concentrations

The indexed peak (111) at $2 \theta=37.1^{\circ}$ correspond to the cubic structure of $\mathrm{NiO}$ nanoparticles which are consistent with the JCPDS (No.47-1049). Figure shows that the diffraction intensity increased for precursor molarity $0.10 \mathrm{~mol} L^{-1}$; it shows that the best crystalline quality of the film is achieved for this precursor molarity. The crystalline size was calculated using Debye-Scherrer formula [10]:

$$
D=\frac{0,9 \lambda}{\beta \cos \theta}
$$

where $\lambda$ is the wavelength of the X-rays used $(1.5406 \mathrm{~A}), \quad \beta$ is the full width at half maximum (FWHM) and $\theta$ is the diffraction angle.

The increasing of the diffraction peaks may indicate to the resulted of the $\mathrm{NiO}$ in good crystallinity [11]. The crystallite size of the $\mathrm{NiO}$ thin films were calculated using the well-known Debye-Scherer's formula Eq. (3.1), the average of the $\mathrm{NiO}$ thin films ranging between 9.72 and $46.62 \mathrm{~nm}$. The changing in the crystallites size leads to the changes in optical properties i.e. band gap energy increased with decreasing crystallites size as shown in Fig. 2.

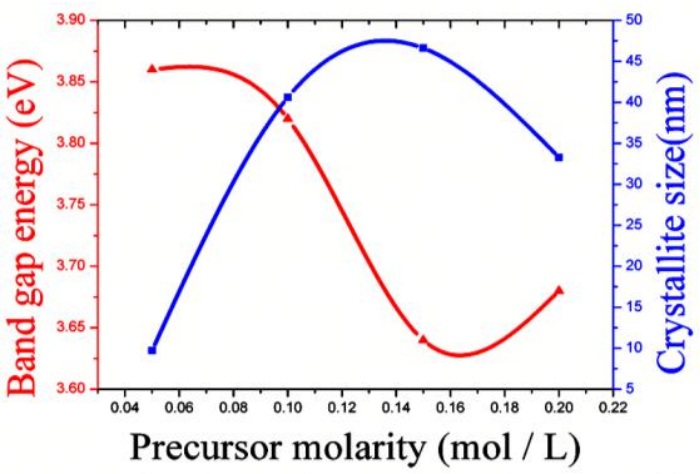

Fig. 2 - The variation of crystallite size and band gap energy $\mathrm{NiO}$ thin films as a function of the precursor molarity

Table 1 - Structural, optical and electrical parameters of NiO thin film at different precursor molarity

\begin{tabular}{|c|c|c|c|}
\hline $\begin{array}{c}\text { Precursor molarity } \\
\left(\mathrm{mol} L^{-1}\right)\end{array}$ & $\begin{array}{c}\text { Crystallite size } \\
(\mathrm{nm})\end{array}$ & $\begin{array}{c}\text { Band gap energy } \\
(\mathrm{eV})\end{array}$ & $\begin{array}{c}\text { Conductivity } \\
(\Omega \mathrm{cm})^{-1}\end{array}$ \\
\hline 0.05 & 9,72 & 3,86 & 0.03306 \\
\hline 0.10 & 40,61 & 3,82 & 0.08961 \\
\hline 0.15 & 46,62 & 3,64 & 0.04125 \\
\hline 0.20 & 33,29 & 3,68 & 0.00698 \\
\hline
\end{tabular}

\subsection{Optical Properties}

Fig. 3 shows the optical absorption spectra of $\mathrm{NiO}$ nanoparticles. The absorption edge of $0.05 \mathrm{~mol} / \mathrm{L}$ was found to be at $326 \mathrm{~nm}$ and of $0.20 \mathrm{~mol} / \mathrm{L}$ was found to be at $343 \mathrm{~nm}$. The absorption spectra of $0.05 \mathrm{~mol} / \mathrm{L}$ show that the absorption edge is slightly shifted towards shorter wavelength when compared to other precursor concentration. The absorption edge of a degenerate semiconductor is shifted to shorter wavelengths with increasing carrier concentration. This shift predicts that there is an increase in band gap value $\left(E_{g}=3.86 \mathrm{eV}\right)$, which is due to the reduction in particle size $(D=9.72 \mathrm{~nm})$. The fundamental absorption, which corresponds to the electron transition from the valance band to the conduction band, can be used to determine the nature and value of the optical band gap. The optical absorption study was used to determine the optical band gap of the nanoparticles, which is the most familiar and simplest method.

The absorption coefficient $(\alpha)$ and the incident photon energy $(h v)$ are related by the expression [12]:

$$
(\alpha h v)=C(h v-E g)^{n}
$$

where $\alpha$ is the absorption coefficient, $C$ is a constant, $h v$ is the photon energy, $v$ is the frequency of the incident radiation, $\mathrm{h}$ is the Planck's constant, exponent $n$ is 0.5 for direct band allowed transition $\left(h v=1239 / \lambda(\mathrm{nm})^{\circ}(\mathrm{eV})\right)$ and $E g$ the band gap energy of the semiconductor. 


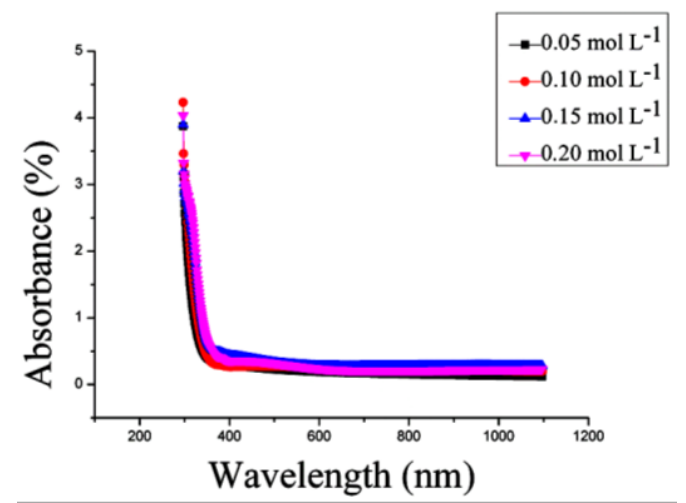

Fig. 3 - Absorbance spectra of $\mathrm{NiO}$ samples for different precursor molarity

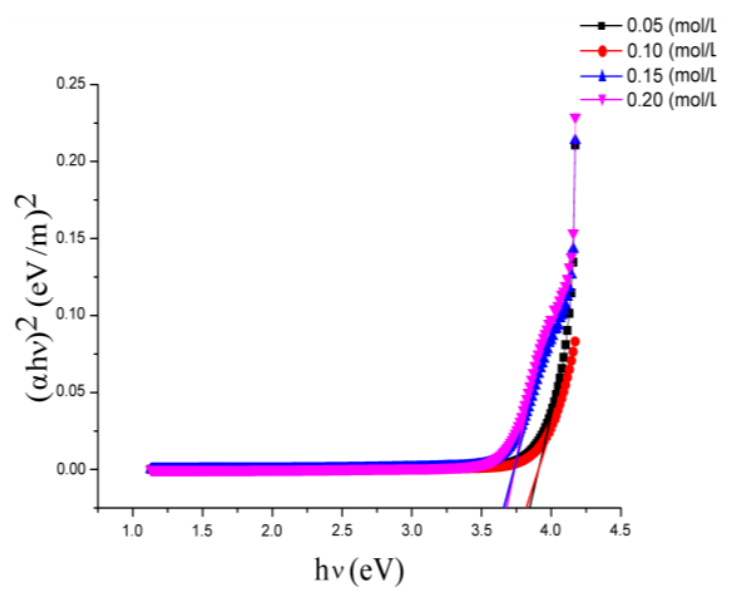

Fig. 4 - Plot of $(\alpha h v)^{2}$ versus incident photon energy $(h v)$ of $\mathrm{NiO}$ nanoparticles

As it was shown in (Fig. 4) a typical variation of $(\alpha h v)^{2}$ as a function of photon energy ( $h v$ ) of $\mathrm{NiO}$ nanoparticles Eq. (2), used for deducing optical band gap Eg, The optical band gap values have been determined by extrapolating the linear portion of the curve to meet the energy axis $(h v)$ [13]. The band gap values were given in Table 1.

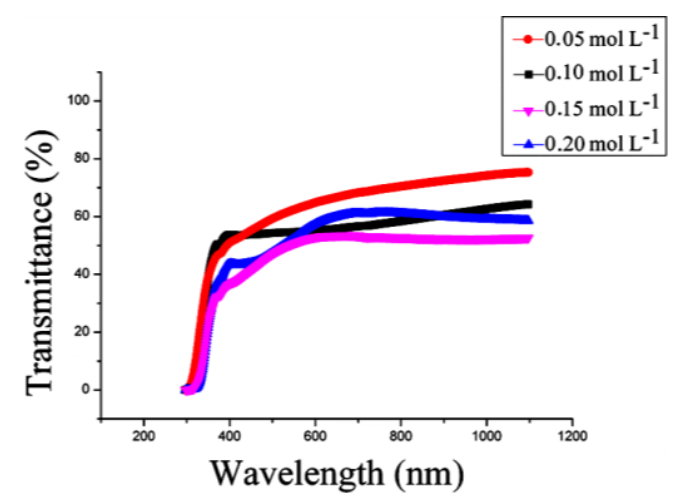

Fig. 5-Transmission spectra of $\mathrm{NiO}$ samples for different precursor molarity

For a transmittance study (Fig. 5), the NiO layer showed very high transmittance of $75.36 \%$, averaged in the wavelength $(\lambda)$ of $300-1100 \mathrm{~nm}$. Suppression of light reflection at a surface is an important factor to absorb more photons in semi-conductor materials. We obtained the reflectance profiles of $\mathrm{NiO}$-coated (Fig. 6). The averaged reflectance values $(300-1100 \mathrm{~nm})$ were significantly lower than $0.203 \%$. Moreover, NiO-coating drives a substantially suppressed reflectance under $0.20 \%$ in $500 \mathrm{~nm}<\lambda<1100 \mathrm{~nm}$. This notifies that the NiO-coating is an efficient design scheme to introduce the incident light into substrate.

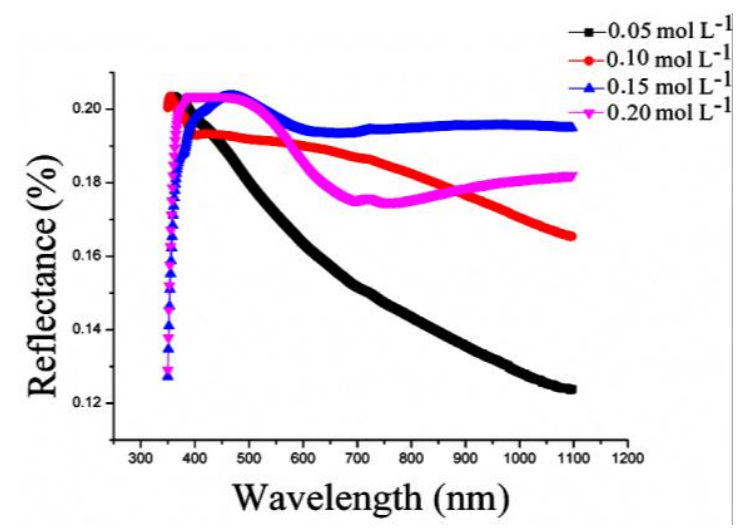

Fig. 6 - Reflectance profiles of $\mathrm{NiO}$ thin film for different precursor molarity

\subsection{Electrical Properties}

The electrical properties of the NiO films are summarized in Table 1. Fig. 7 shows the variation of the electrical conductivity $\sigma$ of $\mathrm{NiO}$ thin films as a function as precursor molarity. As can be seen, deposited films have good conductivity. The maximum recorded value was $0.0896(\Omega \mathrm{cm})^{-1}$ for the $\mathrm{NiO}$ thin film deposited using the molarity $0.10 \mathrm{~mol} \mathrm{~L}^{-1}$. The increase of the electrical conductivity can be explained by the increase in the carrier concentration. Patil et al. [14] have reported that the increase of the electrical conductivity is due to the increase in activation energy with increasing film thickness. This was explained by difference in the experimental conditions of spraying solution, spray rate and cooling of the substrates during decomposition. However, with $0.10 \mathrm{~mol} \mathrm{~L}^{-1}$ precursor molarity, the crystal structure of the film is significantly improved and the grain size is increased, leading to a reduced concentration of structural defects such as dislocations and grain boundaries. Thus, the decrease of the concentration of crystal defects leads in the increase of free carrier concentration. The improvement of crystal quality reduces the carrier scattering from structural defects, leading to higher mobility.

\section{CONCLUSION}

The spray pneumatic technique has been successfully employed to deposit $\mathrm{NiO}$ thin films with different concentrations precursor on glass substrates. All the films showed cubic crystal structure with preferential orientation according to the direction (111). The maximum crystallite size was found $(46.62 \mathrm{~nm})$. We have observed an improvement in the films crystallinity at 0.10 mol L-1 precursor molarity where the peak at position 


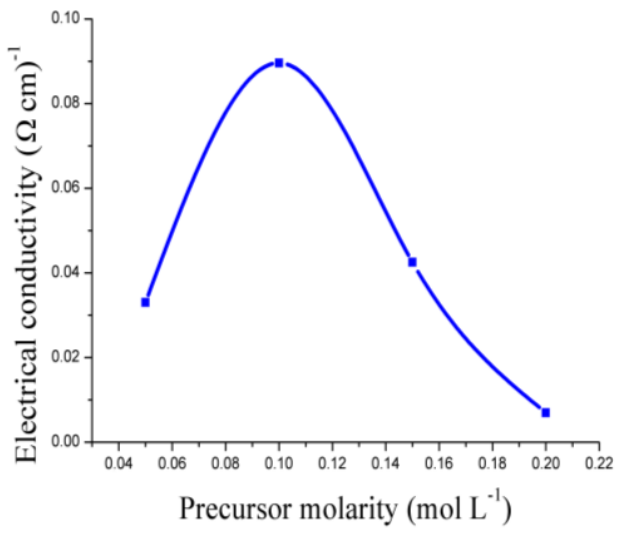

Fig. 7 - Variation of the electrical conductivity of $\mathrm{NiO}$ thin films with the precursor molarity

$37.1^{\circ}$ corresponding to the (111) plans is very sharp, the film obtained at this concentration has higher and sharper diffraction peak indicating an improvement in

\section{REFERENCES}

1. M.A. Abbasi, Z.H. Ibupoto, A. Khan, O. Nur, M. Willander, Mater. Lett. 108, 152 (2013).

2. M.D. Irwin, D.B. Buchholz, A.W. Hains, R.P.H. Chang, T.J. Marks, Proceedings of the National Academy of Sciences, art. No 0711990105, 105 (2008).

3. J. Kim, J.-H. Yun, Y.C. Park, W.A. Anderson, Mater. Lett. 75, 99 (2012).

4. M.-J. Park, J.-Y. Jung, S.-M. Shin, J.-W. Song, Y.-H. Nam, D.-H. Kim, Thin Solid Films 599, 54 (2016).

5. K.C. Wang, P.S. Shen, M.H. Li, S. Chen, M.W. Lin, P. Chen, ACS Appl. Mater. Interfaces 6(15), 11851 (2014).

6. J.H. Yun, J. Kim, Y.C. Park, S.J. Moon, W.A. Anderson, Thin Solid Films 547, 17 (2013).

7. S. Ahn, A.H. Tuan, S. Kim, C. Park, C. Shin, Y.J. Lee, Mater. Lett. 132, 06 (2014). peak intensity compared to other films. The band gap value of $\mathrm{NiO}$ films was found from $3.64 \mathrm{eV}$ to $3.86 \mathrm{eV}$. The high transmittance ( $75.36 \%)$, low reflectance under $0.20 \%$, widened band gap and good conductivity $\left(0.0896(\Omega \mathrm{cm})^{-1}\right)$ obtained for $\mathrm{NiO}$ thin films make them promising candidate for optoelectronic devices as well as window layer in solar cell applications.

\section{AKNOWLEDGEMENTS}

Authors wish to thank Mr. Brahim Gasmi for his assistance in XRD data acquisition from (LPCMA), University of Biskra, Algeria and Pr. Tibarmacine from the university of Biskra, Algeria.

Authors are grateful to the Editor-in-Chief of the Journal of Nano- and Electronic Physics Protsenko Ivan Yuhymovych for a critical reading of the manuscript and his valuable comments.

8. D. Zaouk, Y. Zaatar, R. Asmar, Microelectron. J. 37,5 (2006).

9. A.A. Al-Ghamdi, W.E. Mahmoud, .J. Yaghmour, F.M. AlMarzouki, J. Alloy. Compd. 486, 1 (2009).

10. B.D. Cullity, Elements of X-ray Diffraction (AddisonWesley Publishing Co. Inc.: New York: 1976).

11. R. Charma, A.D. Acharya, S. Moghe, B. Shrivastava, M. Gangrade, V. Shripathi, V. Ganesan, Mater. Sci. Semicond. Process. 23, 42 (2014).

12. R. Sharma, A.D. Acharya, S.B. Shrivastava, M. M. Patidarc, M. Gangradec, T. Shripathic, V. Ganesan, Optik 127(1), 11 (2016).

13. P.M. Ponnusamy, S. Agilan, N. Muthukumarasamy, T.S. Senthil, G. Rajesh, M.R. Venkatraman, D. Velauthapillai, Mater. Charact. 114, 166 (2016).

14. P.S. Patil, L.D. Kadam, Appl. Surf. Sci. 199, 1 (2002). 